\title{
Internationalizing Higher Education: From Grand Plans to Evolving
}

\section{Responses}

\author{
Sefika Mertkan, Ilkay Gilanlioglu and Simon McGrath
}

\begin{abstract}
:
Purpose - This paper explores the complexity of developing into an international institution from the perspective of higher education leaders through the case study of one institution engaged in institutional transformation.

Design/Methodology/Approach - This study employs the qualitative approach and involves in-depth interviews with key institutional managers.

Findings - Findings suggest internationalization is a dynamic change process that goes beyond the rational and predictive elements of internationalization and cannot be confined to the rational planning and grand plans solely at institutional level. Reciprocal influence of different levels of analysis - institution, society and the nation - needs to be acknowledged and internationalization efforts need to go beyond the confines of the institution and extend into the society and the nation as a whole.

Originality/Value - Internationalization of higher education has been widely examined, but the reciprocal influence of different levels of analysis on the internationalization efforts of higher education institutions is thin to which this paper contributes.
\end{abstract}

\section{Introduction}

The internationalization of higher education has become one of the most prominent phenomena of higher education policy, practice and research of the early $21^{\text {st }}$ Century, and has emerged as a core tool of wider development policy for a number of states, particularly small states (Agarval et al., 2007). The majority of higher education institutions now list internationalization as a priority (Knight 2006) while the flow of students choosing to study outside their home countries is predicted to rise from 2.5 million to 7 million between 2005 and 2020 (Altbach et al., 2009). 
For higher education institutions, there is a clear drive to reap the presumed benefits of greater internationalization, with language couched increasingly at each level in terms of return on investments, and in terms of competition (Knight 2004; Stromquist 2007; Foskett and Maringe 2010). At the institutional level, this is tied to institutional identity ${ }^{1}$ change from a national into an international higher education institution (Söderqvist, 2007) embedded in more entrepreneurial institutional cultures (Burnett and Huisman 2010). It includes new marketing and recruitment processes (Wilkins and Huisman 2011), a strong focus on internationalizing the curriculum and enhancing the quality of teaching and learning, and a concern with improving the wider student experience through improved living, catering and leisure facilities (Knight 2007).

Against individualizing and managerialist accounts, however, there is a growing literature that argues institutional internationalization strategies cannot meaningfully be understood outside a wider reading of processes of globalization and marketization (Marginson, 2004; Altbach and Knight, 2007; Naidoo, 2010). For our purposes here, this literature is most useful when it insists on the interplay between the institutional and national levels (Knight, 2004; Marginson and Sawir, 2006; Jones and Olensiyenko, 2011). In this view, institutions operate within national higher education funding and regulation regimes that send powerful signals about the importance of internationalization and which incentivize or discourage certain activities. Even private higher education providers are influenced profoundly in their internationalization activities by national immigration regimes in their home countries and the countries in which they operate.

${ }^{1}$ In this paper, we define institutional identity as "those characteristics of an organization collectively understood by its members to be central, distinctive and enduring" (Corley, 2004) giving the institution its character. 
Such literature is still predominantly institution centric. Most internationalization of higher education research has focused on the institution or the state as a particular level of analysis (Jacob and Meek, 2013; Ma, 2014) largely ignoring "the processes by which organizationbased identities come into existence and come to influence the nature and enactment of identities at other levels" (Ashforth et al., 2010, p. 1144). Through this omission of the interlocking relationships between levels of analysis and the reciprocal influence of these levels on internationalization efforts, this discussion fails to capture in entirety the multifaceted and complex nature of institutional change from national to international, which is a dynamic change process going beyond the rational and predictive elements of internationalization, something that is emerging more strongly in the literature more recently (e.g. de Wit and Hunter, 2015). Through a case study of one institution in one location - that of North Cyprus - we explore how a drive towards internationalization of higher education may, as Knight (2015) suggests, unleash a dynamic set of processes that cannot be confined to institutional level only, but require both states and institutions to develop evolving responses to the opportunities and challenges that emerge at individual, departmental, institutional, national and regional levels (Sanderson, 2008). Such responses are likely to transform the identity and culture of the university (de Wit and Hunter, 2015) and may also have significant effects on the wider culture of the city or nation in which increasingly internationalized campuses are located while the lack of them are likely to hinder the efforts of the institution to grow into an international higher education institution.

We will now turn briefly to the North Cypriot context in which our examination of these issues takes place. Selection of cases is a major and longstanding methodological issue across a number of social science disciplines. Our case is one of the interface between an institution and the larger polity in which it is located, i.e., it is a two-level case. Its selection has two 
main justifications. On the pragmatic level, two of the authors are Turkish speakers and have worked within the local higher education system, and, hence, we have a set of linguistic and cultural resources to facilitate the study. However, at a more methodological level, the case also offers particular attractions. We will talk below about the size and particular dynamics of North Cyprus in order to contextualise the study. At a methodological level, the small size of the state makes the two level case more amenable to study. Moreover, the size of the international student population as a proportion of the total student and national population means that this is a particularly concentrated case of internationalization. In the case selection literature, there is much talk about "most likely" cases, those where we are most likely to find a hypothesis confirmed (cf. Levy, 2008). These are often justified as a means of theory testing that can discount a theory if it does not find empirical purchase where this is most likely. However, in seeing internationalization of higher education as a phenomenon that is both spreading and deepening, we selected North Cyprus as being at the leading edge of change. We do not claim that what we find in North Cyprus is typical of how internationalization is experienced and practised presently. However, as a particularly developed and concentrated case it allows us to see trends that are ongoing elsewhere in far

clearer focus. This offers insights both into how theories of internationalization and institutional / national policies and practices could usefully develop. Hence, it is best seen not so much as an outlier in data terms but a forerunner in terms of evolving trends. This section is followed by a brief description of data gathering and analysis methods. We then move on to critically discuss the key findings, which is followed by the concluding section.

\section{The Context}

Cyprus is an island politically and physically divided into North and South. While the Greekspeaking South is part of the international community and, since 2004, a member of the 
European Union as the only internationally recognized legitimate state of Cyprus, the Turkish-speaking North is recognized as politically legitimate only by Turkey. As a result, North Cyprus has long suffered from internationally-imposed social, political and economic embargoes (UN Security Council, 1983, 1984). Challenges common in many small island state economies such as a limited internal market, outward emigration of skilled human capital and scarcity of natural resources are exacerbated by the lack of international recognition, and economic development has been constrained. Higher education has played an important role in the economic development that has been achieved (Katircioglu, 2010) and has been identified as a key element of the national development strategy (YHB, 2013).

There are ten universities in North Cyprus, two of which are Turkish universities with offshore campuses on the island (http://www.ncyodak.eu/turkce/universities.html), and approximately 70000 students. International students comprise 55000 of these: more than $20 \%$ of the national population (http://www.studyinnorthcyprus.org/). Turkish students are still the majority of international students but there has been a rapid rise in other non-EU students, from 8\% of enrolments in 2007 to $24 \%$ in 2013 (YHB, 2013). This dramatic increase is the result of extensive institutional efforts to increase their share of the international student market and reduce overreliance on students from Turkey (MehtapSmadi and Hashemipour, 2011). This followed a significant decrease in the number of Turkish students in late 2000 s as a consequence of the rapid development of the Turkish higher education sector (Technopolis, 2012).

North Cypriot universities place considerable emphasis on external accreditation of programmes, in keeping with wider international trends (Knight, 2015). Programmes are 
typically accredited by the Turkish Higher Education Council but many also have more international accreditations such as from the Accreditation Board for Engineering and Technology of USA and the Tourism Education Quality programme of the World Tourism Organization.

\section{Methodology}

This paper draws on a larger study on the internationalization of higher education focused on one university in North Cyprus, which as stated above, is an extreme case of internationalization with exceptionally high proportion of international students to national ones and to the overall population in the north of the island. The study adopts a qualitative approach because we were interested in examining the phenomenon in depth and understanding, in its totality, what internationalization means in context rather than seeking generalizable findings. We adopted a qualitative approach because qualitative research is particularly useful "in situations where a detailed understanding of a process or experience" (Bazeley and Jackson, 2013, p. 2) through "situation-related statements, which are empirically well founded" (Flick, 2009, p. 14) is desired. Because research methodology needs to closely fit with the purpose (Bazeley, 2013; Richards and Morse, 2012), qualitative approach was, with no doubt, the quintessential choice.

Data were collected through semi-structured interviews, each lasting around 90 minutes to allow experiential 'realities' of participants to emerge (Miller and Glassner, 2004). For the purpose of this paper, 22 interviews focused on institutional capacity building and leading international higher education institutions were carried out by two of the authors. Interview questions were generated during interviews in response to the dimensions introduced by the 
participants, but the aforementioned focus was maintained throughout the interviews. Participants held various managerial positions, including Vice Rector, Dean and Head of Department, and were selected through purposeful sampling. Specific attention was given to choosing participants with extensive knowledge about the historical roots of internationalization and including diverse perspectives. Participants were provided with the opportunity to determine the language in which interviews were carried out: 18 chose Turkish and four English. All, but one were recorded; extensive notes being taken in the one case where the interviewee preferred not to be recorded. All interviews were transcribed and those in Turkish were subsequently translated into English.

Data analysis was an iterative process of 'progressive focusing' (Schutt, 2015). As the interviews proceeded and transcripts were produced and read, so themes and questions emerged in regular team meetings that were explored in subsequent interviews. Hence, questions were modified in an iterative way throughout the study to further explore emerging themes. One such theme was internationalization as a tripartite concept with institutional, regional and national dimensions, which was introduced during an initial interview and explored during the rest of the interviews. Another was the complex relationship between accreditations, leadership capacity building and institutional development. Codes and subcodes were generated through an iterative process of comparing data for convergence and divergence (Patton, 2014). Recurring regularities were identified and patterns these regularities disclose were later assigned into categories and sub-categories. Specific attention was made to ensure categories are internally homogenous, in that data in each category make a meaningful whole, and externally heterogeneous, in that categories are clearly different from one another. Data were simultaneously examined for cases that do not fit the identified categories. 
Throughout the study, ethical guidelines were closely followed and the requirements of North Cyprus were adhered.iot and international research ethics guidelines were closely followed. Institutional consent to conduct the study was obtained prior to the study commenced and individual informed consent was acquired prior to the interviews. Due to the small number of higher education institutions in North Cyprus, special care was taken to mask contextual information that might reveal the identity of the institution or the participants. Hence, information such as the number and geographical distribution of students, accrediting bodies or the programs accredited is not reported to mask institutional identity and participants' names along with their managerial positions were removed to protect anonymity. Inevitably this ethical imperative was at some odds with our desire to locate the study in the richness of the institution's culture and history. Pseudonyms are used throughout this paper.

\section{Findings}

\section{Internationalization as corporate strategy}

The university engaged in internationalization for the reasons outlined above, predominantly worries about the declining supply of students from Turkey. From the very beginning, universities in North Cyprus needed international students to be viable. Cengiz underlines that "the student population in Cyprus would not be enough for a university to survive ... we were conscious of the definite need for outreaching the international arena". Indeed, he noted also that large numbers of Turkish Cypriots students had always studied abroad, so the domestic market was very weak. Originally, the recruitment focus was on Turkish students. However, 
With the number of non-profit private universities increasing in Turkey and the number of universities increasing in North Cyprus, the Turkish Cypriot and Turkish student population have been shrinking. This caused the university to reconsider its internationalization strategy. This was, in fact, a financial strategy in a sense. (Engin)

To widen its student pool, the university has made internationalization a key element of its overall strategy, which clearly was a response to regional developments in Turkey. This is a level that is largely absent in the literature (Sanderson, 2008), which continues to influence the internationalization efforts and processes at the institutional level. This interrelationship between regional developments and institutional processes and internationalization efforts is dynamic and ongoing, which suggests examining internationalization efforts independent of regional forces portrays a partial picture at best. Hence,

Demographics shift with the shifts in the outside world politically and economically you know. So, if you have an Iranian economic crisis, which there was couple of years ago, that again very quickly impact on number of students and those that are coming to us. So, demographics are a very dynamic one. (Tarık)

Amongst the strategies the institution adopted to enhance its image and differentiate itself was the drive for international accreditation of programs. This was a strategic-level decision made to differentiate the institution from its competitors and position the institution as offering education of international standards in the minds of students and other important stakeholders, which is crucial in establishing an intended image (Brown et al., 2006). Differentiation through image crafting is a need decision makers located at institutions facing global competition increasingly recognize as crucial (Drori et al., 2015). High-quality education sealed by international accreditation bodies was an important intended association in organizational attempts to produce an international identity and an intended image. Quality 
seal, participants agree, helps increase the value of the diploma awarded and demonstrate that the education offered meets international academic standards (Knight 2005), which they state, is the much needed entry into the international community which offers high-quality education to an international student body. Tarık continues:

Having as many departments as possible with something by their name from an external international body conveys the message back to our students, potential student body all around the world ... It's getting the seal and it's putting you, you know, with partners around the world who have done similar things and it makes you a member of that international community in another sort of dimension.

In today's landscape, characterized by "students travelling abroad in the pursuit of certificates and their respective market value" (Naidoo 2006, p. 326), producing "positional goods" (Marginson, 2006) and a sought after external image is increasingly important in attracting students in international markets. This is the intended image the institution communicates to important stakeholders - students and possible international partners.

Thus far we have a fairly classic story of symbolic internationalization as a conscious managerial strategy - the institution has clearly engaged with internationalization for financial reasons and employed strategies with economic motives. It is clear that senior managers have seen internationalization as a potential economic stream, which is one of the rationales for internationalization (Lumby and Foskett, 2015). Indeed, it is a successful story. The university now attracts students from a large number of countries to counterbalance the shrinking number of Turkish Cypriot and Turkish students. However, this is the story of first phase internationalization - of recruitment rather than internal change. As our interviews 
progressed, it became clear that this first phase had triggered the need for transformative internationalization characterized by more complex and challenging processes, which result in "intercultural adaptation, and the successful reconfiguration of "identity"” (Gu et al., 2010, p. 7).

\section{The emergence of a pluralist university}

The lived experience of internationalization of this university has been profoundly shaped by the uneven nature of the internationalization project when understood in the simple terms of student recruitment. It is widely accepted internationally that some programs are more attractive to international students than others. This is normally couched in human capital investment terms: the costs of international student migration are high and so international students will concentrate in programs that offer the highest likely rate of return on their investment. Thus, programs in finance or engineering will typically be more attractive to international students than will those in ancient history or philosophy. However, the university is also experiencing a countervailing dynamic. Turkish Cypriots too are large scale international student migrants and many use the same logic to leave the country to study high return subjects. Thus, large parts of the university are heavily weighted towards foreign student numbers.

At the same time, however, there are professions where local content remains highly important, such as education and law. Thus, these faculties remained heavily oriented towards Turkish Cypriot and Turkish students creating multiplicities of models and multiple organizational identities (Pratt and Foreman, 2000). Consequently, the University found itself with a powerful, though not complete, bifurcation between international- and domestic- 
oriented faculties. One outcome of this is the need to build a policy for the language of instruction that reflects these realities. Thus, some parts of the university are predominantly Turkish-medium, whilst others are English-medium. Elsewhere, faculties and departments offer courses in both languages but with very little bilingual education taking place. However, this is not the only means used to diversify, but also the type of programs and mode of instruction - "you may see heavy internationalization in one area of a curriculum within a place and one much more national and these things start to co-exist" (Tarkk).

Whilst many international students are attracted by the possibilities of learning in English, and come from such countries as Nigeria, the university has also been successful in its marketing of itself to the wider Turkic world. Whilst Turkish is the most prominent and widest spoken member of the Turkic language group, it accounts for less than half of all Turkic speakers. Rather, Turkic speaking populations are found from Eastern Europe through to Siberia and Western China, with particular concentrations in the Central Asian Republics. Many students from these states are coming to the university. Ozan explains how this has led to a new dynamic amongst international students:

While you offer English programmes for foreign students and melt a small number of students from Turkey and students from North Cyprus in the same pot, you accept Turkish students to your Turkish programmes. ... In the meantime, students such as Kazakhs, Kirghiz, Turkoman, who know Turkish even if they are foreign, had problems in English programmes and moved to Turkish programmes. So, one way or the other, you manage to keep people from different cultures in the same faculty, but not in the same programme or in the same class. 
However, returning to the importance placed on international accreditation, we should not be surprised to see that the vast majority of the programmes accredited by international organizations are English medium. Though accreditation is primarily a strategy for attracting international students, the planned strategy of gaining accreditation in order to market programs more successfully to international students had evolved into a process of internal development. All participants from departments and faculties accredited by an international organization emphasize the accreditation process has acted as a catalyst for change, transforming departments by making them more aware of international good practices and then encouraging them to adopt and adapt these to their own contexts. Thus, the process of accreditation made the programs more international at the level of administration. Cem argues,

My graduates are all around the world. I need to reach them, I need to identify the weaknesses of the education they received, I need to fix these and then measure again - Continuous Improvement Cycle. I need to do this .... And when doing this, I need to consider multiculturalism and multinationalism.

Accreditations have also changed the departments in terms of the pedagogy and assessment as Cengiz states,

They have standards. You prepare the reports according to those standards and you get to see your deficiencies ... We were criticized for having an exam-weighted system and for not sufficiently assessing students' work outside the class. We sat down and took a decision: the total of a mid-term, a final, and quizzes cannot exceed $60 \%$ in our faculty. $40 \%$ is devoted to the student. Well, what is the instructor 
supposed to do? She offers field trips, small assignments, projects, and therefore we added variety to the student's portfolio.

Clearly, through accreditations, departments have changed not just in terms of the growth in international student numbers first intended; rather, they have developed a more international outlook.

\section{The dynamics of becoming internationalized}

The above example illustrates that diversification of the student body is not the end point of internationalization at the university. Rather, this success has generated a growing realization that internationalization fundamentally changes the institution (cf. de Wit and Hunter, 2015; Knight, 2015). As Merve notes, the need for institutional change has emerged "all the way from course syllabi to general policies of the university”. She continues:

Maybe you need to change your teaching methods because the culture of the student body is different. I love my West African students because they tend to have debating skills. They have a debating culture and this works fantastically well.

Thus, internationalization leads staff to experience different learning cultures and experiences and, where successful, for them to build these into their pedagogic repertoires (Bennett, 1993; Sanderson, 2011). This is change in response to different forms of knowings, knowledges and experiences the international student body brings (Ilieva et al., 2014). 
It is not only academic practices that change in response to internationalization, Banu stresses. The university staff needs to be diversified to better cater for the needs of the international student body. Put simply, “this necessitates international academic staff” (Cem). Talking about the psychological support staff, Banu states:

They have begun to reflect things they wouldn't speak out before. Perhaps a foreign psychologist is needed ... the need perhaps for recruiting someone there who comes from that culture because unfortunately most of us don't know the cultural elements.

Senior staff realize that internationalization fundamentally changed the university. As Tarık notes, "not only the demographics of the university has changed, but the character has", towards what Burak calls a more "international identity". Banu likens this process to "a rolling snowball developing as it gets larger and undergoing a metamorphosis as it develops".

However, there are concerns that students are not mixing. The dominant staff view seems to be that international students need to integrate: "their cultures are different, their beliefs are different, their needs are different, and their ethics are different. What is important is to get these melted in the same pot" (Ozan). However, this melting pot metaphor is very different from the notion of the pluralist university above, in which there is not one large pot in which all ingredients are mixed, but rather a buffet of different flavors of internationalization in different programs, schools and faculties. Interestingly, there was little apparent concern with the internationalization of local student experience. Interviews uncovered little concern about the development of intercultural competencies (Deardorff, 2006) amongst Turkish Cypriot students, or, indeed, a focus on how national and international students interacted (Leask, 2009) beyond a more deficit-led view of international students remaining in their ethnic 
groupings. This suggests that the internationalization process within the university is far from complete.

From the internationalized university to the internationalized community

Staff also had realized that the forces unleashed by internationalization did not remain confined to its campus. Rather, the process was also transforming the community in which the institution is located. As such, they draw attention to the relational sense of context where "actions taken in one context create outcomes and conditions which can permeate through these interlocking relationships to influence subsequent actions in other contexts" (Anderson, 2010). As Tarık notes: "it's not just what's happening in the classroom, what's happening at the university, it's what is happening outside as well ... It's quite complex and long term”. He continues:

We have relationships, dependencies with other sectors. So, how well are the local police able to deal with Africans, you know, when they aren't actually able to communicate with each other and how these people are managing if they need health services?

Banu sums up, “[Students] don’t live only on campus ... we don’t live in a vacuum”.

However, this realization of the way that internationalization's effects spread beyond the campus is largely driven by an experience of the challenges that this has caused for the university. Participants consistently spoke of how community-related problems and being nested in a community that has yet to develop an international identity negatively influence organizational associations, the information students and other stakeholders hold about the university and its reputation, which "may be influenced by a variety of outside sources" (Brown et al., 2006, p. 105) . Orhan is blunt about this: "I believe the university has fulfilled 
the requirements for internationalization by using all its capacity, but the city has failed .... The city should stop seeing students as a source of money". Accommodation is becoming an increasingly tense issue due to rapid increases in international student numbers. Participants agree such cases reflect deeper issues in the community such as the lack of concern for international student needs, an observation echoed by Can who argues that, as a community, "more thought needs to be given to what we can do to make incoming students' lives easier, to provide better opportunities".

There is a strong sense that the community does not have an international identity and being embedded in a community with limited exposure to internationalization prior to internationalization of higher education institutions hinders institutional efforts to develop into an international institution. The university's success in growing international students, though reflected in the national development strategy, has not been anticipated within the municipality and that local people were simply not ready for the massive demographic change.

Unfortunately, the public is not well aware of this - what this university means to the city ... By chasing short-term profits; we actually inflicted long-term wounds in terms of the image. That is, the feeling that Cyprus is expensive, that the craftsmen and the landlords are exploiting [the students] is not a feeling that could be eradicated easily because all this is shared in the social media. They just remain there. (Banu)

Consequently, participants feel the local government has left the university alone in its quest for internationalization: 
What is important is not recruiting students, but the quality of life you offer once they are here. We believe we have done our job as the university, but the community has a big role to play. The municipality has a big role to play .... Unfortunately, I have not seen them doing anything about this until today. (Orhan)

Similar concerns were raised about the central government and its influence on the university. Simply put by Turgay "any negativity caused by the city, any negativity caused by the country seriously disturbs the student and that dissatisfaction can go from ear to ear" adversely influencing the reputation of the university. With regional and national qualities playing a significant role in international students' choice of destination (Cubillo, Sanchez, and Cervino, 2006; Singh, Schapper, and Jack 2014), this becomes crucial.

However, the story is not entirely negative. Just as the university has grown in its understanding of the complexities of internationalization, so there is a sense that North Cypriot society is beginning to adapt in more positive ways. Internationalization is a complex multi-directional change process invariably changing the institution and the community. Kerim thinks that "people are beginning to accept these students because somehow they realized that the number of students is not decreasing, it's increasing." However, the international literature on student migrants' experiences reminds us that the process is not simply one of the host communities becoming more welcoming to incomers. Rather, there is much evidence regarding the understandable tendency of many students to value their own communal ties. Internationalization is not a uni-directional process through which the community comes to adapt to the international student population. Rather, it is a reciprocal process where the international student population also changes as their search for communal unity within growing diversity might hinder integration. In the university, too, there were 
some concerns that international students might be marginalizing themselves through such processes.

they go and form you know mini Nigeria, mini Lagos outside the campus and then the integration is not happening. The community is not absorbing them because they are setting out their own communities. (Tarık)

This longing for communal unity within growing diversity is not unique to this interview. As above, there appears to be a sense of international students not integrating with each other or the community regardless of the change in the perception of the society. In such cases, unity within diversity is maintained; however, diversity within unity might go astray.

We have written about this being a process of cultural change that is ongoing and it is clear that there is still much to be done within the university as well as beyond it to bring the borders down among different student groups, get them engage with each other while also supporting their integration with the community.

\section{Conclusion}

Internationalization leads to and is influenced by unpredicted changes at multiple levels institution, society and nation. It is important for our theoretical accounts to capture more of this dynamism and move away from the inference that internationalization is a process of rational planning by university leaders. 
Rational planning clearly did take place in this case. Turkish Cypriot universities faced a major threat in maintaining student numbers and embarked on a very sensible process of international recruitment. They built effective marketing approaches, including a range of international accreditations. However, it is clear that the effects of success were not fully understood at the outset. Greater international student numbers began to produce a range of effects on campus. A culture of considerable departmental and faculty autonomy resulted in a pluralistic approach in which different programs and different schools and faculties took distinct approaches reflecting whether they were primarily oriented towards the development of local or international professionals - leading to a buffet of actual language policies and practices. The importance of departmental / faculty level analysis is one finding we would stress.

However, it is clear that internationalization is far deeper than questions of medium of instruction. Staff are faced with new challenges of intercultural teaching and how to understand and interact with a very different student body, both in the classroom and beyond (cf. Deardorff 2006; de Wit and Hunter 2015; Knight 2015). This calls for transformative change, which is challenging anywhere but may bring particular difficulties in a fairly homogenous and small community.

The success in recruiting non-Turkish students has led to many internal organizational changes but the cultural changes required of staff may be the most challenging internal dimension. However, for the university increasingly the focus is moving on to the challenges for students living in a national culture, which lacks an international identity - a culture that is far more slowly changing to respond to their needs. The university has come to realize that 
its internationalization project is being undermined by students' poor experiences of living in North Cyprus. There is frustration too with the national and civic governments. Whilst internationalizing higher education has become an important part of national development strategy, from the university's perspective there is little sense of this being thought through as to what it required in practice at the micro and meso levels. Such challenges are likely to be far greater in larger jurisdictions where the geographic and cognitive distance between governments and universities is greater.

The case leads us to emphasise that the internationalization of higher education is a process. Universities use internationalization to respond to opportunities and threats in their environment but progress towards internationalization in quantitative terms throws up a set of organizational and cultural challenges that mean that a university has to start internationalizing at a deeper and more transformative level, as recent developments in the literature have emphasized (de Wit and Hunter 2015; Knight 2015).

The use of a small island case study brings into the sharpest relief the more general issue of how these internal university processes of deepening internationalization cannot remain within the confines of the campus. Indeed, internationalization may be undermined by the negative experiences of international students in wider society: a message that resonates with the well-publicized experiences of individual international students in a number of countries.

Just as internationalization changes universities at a qualitative as well as quantitative level, so it will have similar impacts on societies, most profoundly in deeply quantitatively internationalized settings such as North Cyprus. The proportion of the national population 
there that comprises international students means that it is on the leading edge of dealing with societal internationalization through the internationalization of higher education.

The internationalization of higher education, therefore, unleashes two complex dynamics. First, the process drives organizational and cultural change within the university as it reacts to the effects of increasing international student numbers. Second, this then has spill-over effects into the wider society. How the two of these dynamics are managed will have profound implications for the future success or failure of higher education internationalization. This must become a major focus of both policy and research. 


\section{References}

Agarwal, P., Said, M., Sehoole, M., Sirozi, M., and de Wit, H. (2007), “The dynamics of international student circulation in a global context", in Altbach, P. and Peterson, P. (Eds.), Higher Education in the new century: Global challenges and innovative ideas, Sense, Rotterdam.

Altbach, P. and Knight, J. (2007), “The internationalization of higher education: Motivations and realities", Journal of Studies in International Education, Vol. 11 No. 3-4, pp. 290-305.

Altbach, P., Reisberg, L., and Rumbley, L. (2009), Trends in global higher education: Tracking an academic revolution, UNESCO, Paris.

Ashforth, B.E., Rogers, K.M., and Corley, K.G. (2011), “Identity in Organizations: Exploring Cross-Level Dynamics”, Organization Science, Vol. 22 No. 5, pp. 1144-1156.

Bazeley P. (2013), Qualitative Data Analysis: Practical Strategies, Sage, London and Thousand Oaks.

Bazeley, P. and Jackson, K. (2013), Qualitative Data Analysis with NVIVO, Sage, London and Thousand Oaks.

Bennett, M. J. (1993), “Towards ethnorelativism: A developmental model of intercultural sensitivity", in Paige, R. (Ed.), Education for the intercultural experience, Intercultural Press, Yarmouth, pp. 21-71.

Brown, T.J., Dacin, P.A., Pratt, M.G., and Whetten, D.A. (2006), “Identity, Intended Image, Construed Image, and Reputation: An Interdisciplinary Framework and Suggested Terminology”, Academy of Marketing Science, Vol. 34 No. 2, pp. 99-106.

Burnett, S. A. and Huisman, J. (2010), 'Universities' responses to globalisation: The 
influence of organizational culture", Journal of Studies in International Education, Vol. 14 No. 2, pp. 117-142.

Cooke, P. (2004), “The role of research in regional innovation systems: New models meeting knowledge economy demands", International Journal of Technology Management, Vol. 28 No. 3-6, pp. 507-533.

Corley, K.G. (2004), "Defined by our strategy or our culture? Hierarchical differences in perceptions of organizational identity and change", Human Relations, Vol. 57 No. 9, pp. $1145-1177$.

Cubillo, J., Sanchez, J., and Cervino, J. (2006), “International students' decisionmaking process", International Journal of Educational Management, Vol. 20 No. 2, pp. 101-115.

Deardorff, D. (2006), "Identification and assessment of intercultural competence as a student outcome of internationalization", Journal of Studies in International Education, Vol. 10 No. 3, pp. 241-266.

de Wit, H. and Hunter, F. (2015), “Trends, issues and challenges in internationalization of higher education: Where have we come from and where are we going?", in McGrath, S. and Gu, Q. (Eds.), Routledge Handbook of International Education and Development, Routledge, London.

Foskett, N. and Maringe, F. (2010), Globalisation and Internationalization in Higher Education, Continuum, London.

Flick, U. (2009), An Introduction to Qualitative Research (4 ${ }^{\text {th }}$ ed.), Sage, London and Thousand Oaks.

Jones, G. and Oleksiyenko, A. (2011), “The internationalization of Canadian university 
research: A global higher education matrix analysis of multi-level governance",

Higher Education, Vol. 61 No. 1, pp. 41-57.

Gu, Q., Schweisfurth, M., and Day, C. (2010), “Learning and Growing in a 'Foreign'

Context: Intercultural Experiences of International Students", Compare: A Journal of Comparative and International Education, Vol. 40 No. 1, pp. 7-23.

Ilieva, R., Beck, K., and Waterstone, B. (2014), “Towards Sustainable Internationalization of Higher Education”, Higher Education, Vol. 68 No. 6, pp. 875-889.

Katircioglu, S. (2010), “International tourism, higher education and economic growth: The case of North Cyprus", The World Economy, Vol. 33, No. 12, pp. 1955-1972.

Knight, J. (2004), “Internationalization remodeled: Definition, approaches, and rationales", Journal of Studies in International Education, Vol. 8 No. 1, pp. 5-31.

Knight, J. (2006), “Internationalization of higher education: New directions, new Challenges”, 2005 IAU Global Survey Report, International Association of Universities, Paris.

Knight, J. (2007), "International brings important benefits as well as risks", International Higher Education, Vol. 46, pp. 8-10.

Knight, J. (2011), “Education hubs: A fad, a brand, an innovation?", Journal of Studies in International Education, Vol. 15 No. 3, pp. 221-240.

Knight, J. (2015), "Meaning, rationales and tensions in the internationalization of higher Education", in McGrath, S. and Gu, Q. (Eds.), Routledge Handbook of International Education and Development, Routledge, London. 
Leask, B. (2009), "Using formal and informal curricula to improve interactions between home and international students", Journal of Studies in International Education, Vol. 13 No. 2, pp. 205-221.

Levy, J. (2008), “Case studies: Types, designs, and logics of inference”, Conflict Management and Peace Science, Vol. 25, pp. 1-18

Lumby, J. and Foskett, N. (2015), “Internationalization and culture in Higher Education”, Educational Management Administration and Leadership.

Marginson, S. (2004), "Competition and markets in higher education: a 'glonacal' Analysis", Policy Futures in Education, Vol. 2 No. 2, pp. 175-244.

Marginson, S. (2006), "Dynamics of national and global competition in higher education", Higher Education, Vol. 52 No. 1, pp. 1-39.

Marginson, S. and Sawir, E. (2006), “University leaders' strategies in the global environment: A comparative study of Universitas Indonesia and the Australian National University", Higher Education, Vol. 52 No. 2, pp. 343-373

Miller, J. and Glassner, B. (2004), “The 'inside' and the 'outside': Findings realities in Interviews", in Silverman, D. (Ed.), Qualitative Research: Theory, Method and Practice, Sage, London, pp. 125-139.

Mehtap-Smadi, S. and Hashemipour, M. (2011), "In pursuit of an international education destination: Reflections from a university in a small island State", Journal of Studies in International Education, Vol. 15 No. 5, pp. 409-428.

Naidoo, R. (2006), “International education: A tertiary-level industry update”, Journal of Research in International Education, Vol. 5 No. 3, pp. 323-345. 
Naidoo, R. (2010), "From ivory towers to international business: Are universities export ready in their recruitment of international students?", Journal of Studies in International Education, Vol. 14 No. 1, pp. 5-28.

Patton, M. (2014), Qualitative Research and Evaluation Methods (4 ${ }^{\text {th }}$ ed.), Sage, Thousand Oaks.

Porter, M. (2000), “Location, competition, and economic development: Local clusters in a global economy", Economic Development Quarterly, Vol. 14 No. 1, pp. 17-33.

Pratt, M.G. and Foreman, P.O. (2000), “Classifying managerial responses to multiple organizational identities", Academy of Management Review, Vol. 25 No. 1, pp. 18-42.

Richards, L. and Morse, J.M. (2013), ReadMe First for a User's Guide to Qualitative Research ( $3^{\text {rd }}$ ed. $)$, Sage, Thousand Oaks.

Sanderson, G. (2011), “Internationalization and teaching in higher education”, Higher Education Research \& Development, Vol. 30 No. 5, pp. 661-676.

Sanderson, G. (2008), "A foundation for the internationalization of the academic Self", Journal of Studies in International Education, Vol. 12 No. 3, pp. 276-307.

Schutt, R. (2015), Investigating the social world: The process and practice of research $\left(8^{\text {th }}\right.$ ed. $)$, Sage, Thousand Oaks.

Sidhu, R., Ho, K. C., and Yeoh, B. (2011), "Emerging education hubs: The case of Singapore", Higher Education, Vol. 61 No. 1, pp. 23-40.

Singh, J., Schapper, J., and Jack, G. (2014), “The importance of place for international students' choice of university: A case study at a Malaysian university”, 
Journal of Studies in International Education, Vol. 18 No. 5, pp. 463-474.

Stromquist, N. (2007), "Internationalization as a response to globalization: Radical shifts in university environments", Higher Education, Vol. 53 No. 1, pp. 81-105.

Technopolis (2012), Kuzey Kıbrıs Türk Cumhuriyeti Yükseköğrenim Sektörüne İlişkin Durum Tespiti Çalışması: KKTC Yükseköğrenim Stratejisi ve Eylem Planı Önerisi, Yardım Heyeti Başkanlığı, Lefkoşa.

UN Security Council (1983), Resolution 541 (S/RES/541). See:

http://www.un.org/en/sc/documents/resolutions/1983.shtml.

UN Security Council (1984), Resolution 550 (S/RES/550). See:

http://www.un.org/en/sc/documents/resolutions/1983.shtml.

Wilkins, S. and Huisman, J. (2011), "Student recruitment at international branch campuses: can they compete in the global market?", Journal of Studies in International Education, Vol. 15 No. 3, pp. 299-316.

Yardım Heyeti Başkanlığı (YHB) (2013), KKTC 2013 Ekonomi Durum Raporu, Yardım Heyeti Başkanlığı, Lefkoşa. (in Turkish) 